\title{
Pharmaceutical Dissolution
}

National Cancer Institute

\section{Source}

National Cancer Institute. Pharmaceutical Dissolution. NCI Thesaurus. Code C134253.

Test to determine compliance with the requirements of the material of interest dissolving into solution. 